\section{A Lenda dos Anjos}

Michel Serres

São Paulo, Aleph, 1995. 304p.

Quando o chamado leitor "sério" se depara numa livraria com uma vistosa publicação sobre os anjos, é de se esperar algum tipo de sarcasmo, já que é muito forte a tendência a confundi-la com mais um lançamento da “angelologia de auto-ajuda” que prolifera no mercado editorial. O tema dos anjos, para este leitor, está marcado pela frivolidade e não merece atenção. Entretanto, para aqueles que já conhecem Michel Serres, o seu nome encabeçando a obra já é suficiente para destacá-la do fundo indiferenciado da moda. Moda, aliás, que o filósofo não reconhece, já que, para ele, a cultura ocidental jamais deixou de se interessar pelos anjos e com eles convive há séculos.

O que nos oferece, entretanto, não é exatamente uma angelologia, a não ser que considerássemos toda sua extensa obra de filósofo e historiador das ciências como uma grande angelologia; possibilidade que o próprio autor não descarta. De fato, Michel Serres admite que $A$ Lenda dos Anjos, genericamente classificado como um ensaio sobre a comunicação, consiste numa espécie de síntese de suas realizações filosóficas. Portanto, uma obra-chave para o conhecimento do pensamento e do universo de interesses desse formidável intelectual de nosso tempo, que não apenas vem contribuindo para uma reflexão filosófica da problemática moderna da comunicação, mas que, principalmente, vem colocando o conceito de comunicação no centro da reflexão filosófica.

A edição brasileira segue à risca a edição original francesa, uma vez que, neste caso, o tratamento gráfico-editorial não é um elemento acessório do livro, mas soma-se ao texto compondo o todo do trabalho oferecido pelo filósofo. O que temos, assim, é uma meditação dialogada sobre as redes do mundo acompanhada de um álbum magnifica e significativamente ilustrado (onde se misturam história da arte e fotos do real: circuitos eletrônicos, traçados cartográficos, fenômenos da natureza e a miséria do mundo). As imagens, os textos que acompanham as imagens e o texto-mãe sob a forma de um diálogo interconectam-se segundo linhas de associação sutis que tecem um outro nível de significação que é, sem dúvida, aquele que melhor acolhe as intuições filosóficas do autor. É sobretudo neste nível de constituição dos sentidos - que se dá nos múltiplos interfaceamentos das diferentes formas pelas quais o pensamento se faz representar - que podemos apreender plenamente o que há de mais singular $e$ original em suas idéias. Pode-se dizer que o livro sugere a estrutura de um hipertexto 
(como diria seu amigo e colaborador, o “antropólogo da informática”, Pierre Lévy, a quem, entre outros, Michel Serres dedica o livro). E, de fato, estamos diante de uma filosofia toda feita conexões, associações, ligações, aproximações, passagens...

Mesmo nos meios intelectuais franceses, a projeção deste autor de 67 anos, que já publicava prolificamente há pelo menos duas décadas, é relativamente recente, justificandose, portanto, apresentá-lo brevemente para o leitor brasileiro. A Lenda dos Anjos, como já foi assinalado, possui esta virtude de introdução geral ao pensamento e à obra do filósofo. Nas últimas páginas da cuidada edição, Michel Serres apresenta uma relação de suas obras já publicadas, organizando-as sob três rubricas: "Equilíbrio e fundações", "Energia e transformações" e "Mensageiros, mensagens e mensageirias". Numa entrevista à imprensa literária francesa, o autor relata que foi durante a confecção do capítulo "Mensageirias" que percebeu que toda sua obra estava de alguma forma ligada a uma destas três etapas da história do trabalho, segundo suas próprias formulações teóricas: a era dos "carregadores", filha da revolução agrícola e representada nos mitos de Atlas e Hércules; a era dos "transformadores", filha da revolução industrial e representada nos mitos de Vulcano e Prometeu; e, filha da revolução informacional (e de uma revolução “pedagógica”, segundo Serres, em grande parte por se realizar), a era dos

"mensageiros", anunciada pelas antiqüíssimas lendas dos anjos que povoam as grandes religiões monoteístas (judaísmo, cristianismo, islamismo).

Uma dentre várias conseqüências deste ponto de vista sobre a história dos modos de transformação humana do mundo é encontrada nesse mesmo capítulo: Michel Serres argumenta que a "crise" de nosso tempo se deve fundamentalmente ao prolongamento do esquema prometáico do trabalho, que teve seu apogeu no século XIX, quando já deveríamos ter passado para o esquema das mensageirias. "Nós já só trabalhamos para reparar os estragos do trabalho... Nós já transformamos e exploramos bastante o mundo, é chegado o tempo de compreendê-lo." Para o pensador, o remédio para o desemprego, p.ex. - problema gerado pelo efeito das novas tecnologias sobre o antigo trabalho - deve ser procurado, de preferência, no terreno das mensageirias...

Mas este é apenas mais um ponto luminoso na constelação de idéias descortinadas ao longo da obra. Há outro, entretanto, que merece destaque, por revelar um dos traços mais significativos das intervenções filosóficas deste autor: em toda sua obra, Michel Serres não cessou de trançar os liames, lançar pontes e passarelas entre as artes $e$ as ciências, entre as ditas ciências exatas $e$ as ditas humanas, entre natureza e cultura, entre religião e 
razão. Sua máxima: "pas d'univers sans mélange". A Lenda dos Anjos não faz outra coisa: é um livro sobre a ciência, sobre a inteligência, sobre a técnica, em que a sensibilidade religiosa, amorosa e patética está totalmente presente. Nas suas palavras, comentando o livro: "Eu quis aproximar o coração e a razão. $\mathrm{O}$ anjo possui ao mesmo tempo um olhar acerado de inteligência e um olhar piedoso." No livro, escreve: "o anjo permite ao mesmo tempo compreender, por finas técnicas, o funcionamento das coisas, dos homens ou dos utensílios e de expor a moral, coisa rara." $\mathrm{O}$ anjo (do grego angelos, mensageiro) faz a mediação entre estes dois universos por meio do diálogo de Pia e Pantope, que se dá num dos grandes nós das redes mundiais que é o aeroporto Charles de Gaulle em Paris. Pia é médica do aeroporto, "imóvel e atenta ao movimento"; Pantope é inspetor de uma companhia aérea e "gira em torno do mundo". É por meio do diálogo destas duas sensibilidades que chegamos à visão do planeta como uma imensa mensageiria.

Trata-se do diálogo como forma privilegiadamente filosófica (o autor se confessa, dentro do gênero, um admirador irrestrito de Diderot). Mas o diálogo de Pia e Pantope também é o diálogo de um homem e uma mulher $e$, no caso, trata-se de um "diálogo amoroso". Michel Serres não dissimula nem um pouco essa dimensão e nem perde a oportunidade, ao comentar este aspecto do livro, de revelar mais um ângulo das suas concepções sobre a comunicação: "Eu fiz dialogar um homem e uma mulher porque meu livro é também um livro sobre o amor, o que jamais ousara abordar. Mas quando se escreve sobre a comunicação, é preciso ter a coragem de ir até o fim: a verdadeira comunicação entre os homens é o amor."

Nesta era que se autonomeia "comunicacional" e depois pratica as mais constrangedoras reduções do conceito, mergulhar no universo "angelical" oferecido pela obra de Michel Serres pode significar uma experiência única de desopressão intelectual $e$ libertação criativa. E esta parece ser, mais do que nunca, fundamental para a compreensão $e$ o enfrentamento otimista de alguns dos nossos principais desafios contemporâneos, o que certamente passa por se alcançar uma conceitualização mais ampla (até mesmo ecológica e cosmopolítica, mas, sobretudo, eticamente comprometida) do que seja comunicação.

Ricardo Rodrigues Teixeira Departamento de Medicina Preventiva Faculdade de Medicina, USP 


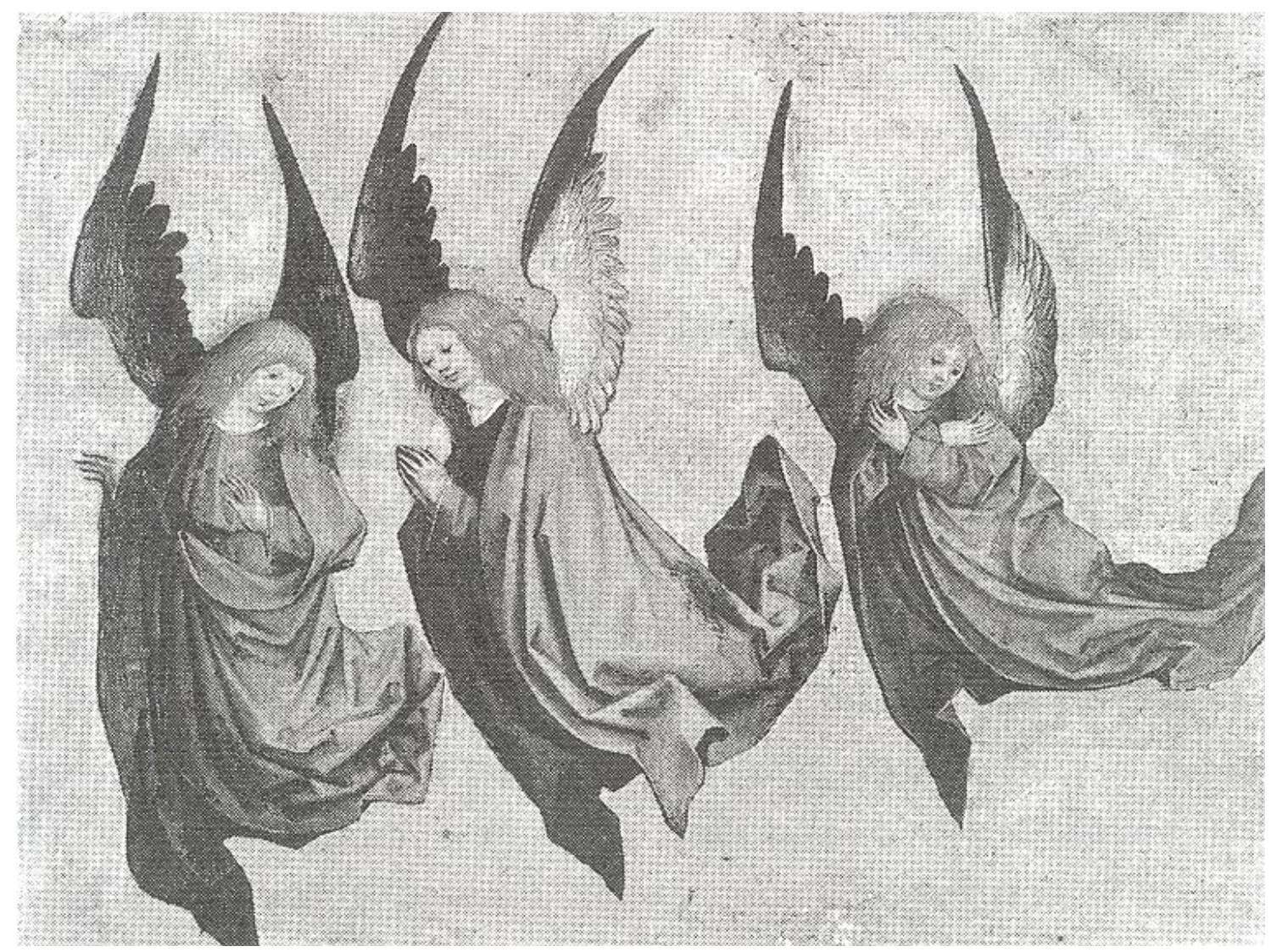

Três anjos alados, MESTRE DO LIVRO DE CASA, 1460/1490, Museu de Arte de Basiléia, Suíça. 